\title{
To study the impact of psychiatry posting on attitude towards psychiatry and estimated likelihood of psychiatry as a career choice in female interns in North India
}

\author{
Sunny Garg', Alka Chauhan², Mahender Singh ${ }^{3}$, Mariya Khan", Sanjeet Singh ${ }^{5}$, \\ Kirti Bansal ${ }^{6}$ \\ ${ }^{1}$ Senior Resident, ${ }^{2}$ Junior Resident, ${ }^{4}$ Intern, Department of Psychiatry, Bhagat Phool Singh Government Medical \\ College For Women, Khanpur Kalan, Sonipat, Haryana, India, ${ }^{3} J u n i o r$ Resident, Department of Psychiatry, Indira \\ Gandhi Medical College, Shimla, Himachal Pradesh, India, ${ }^{5}$ Assistant Professor, Statistician, Department of \\ Community Medicine, Bhagat Phool Singh Medical College For Women, Khanpur Kalan, Sonipat, Haryana, India, \\ ${ }^{6}$ English Tutor, Kirori Mal College, Delhi University, New Delhi, India
}

\section{A B S T R A C T}

Background: Psychiatric disorders have been rising in last few years and emerging as leading cause of disease burden. Psychiatry as a discipline of medicine carry a lot of stigma due to which there is a lack of young medical students or professionals in choosing psychiatry as a career. Aims and Objectives: To study the impact of psychiatry posting on attitude towards psychiatry and estimation of likelihood of Psychiatry as a career choice in female interns. Materials and Methods: A cross sectional observational study of 112 female interns who met the Inclusion criteria. A written informed consent was obtained from the interns. A selfassessable ATP-30 scale was used to assess the attitude of the interns, this questionnaire was filled by the interns on the first day and after the two weeks of their posting in psychiatry department. The data collected was analysed with the help of SPSS version (21.0) info. Results: Ninety-eight interns were considered for further analysis because 14 female interns fulfilled the exclusion criteria. More than $95 \%$ interns reported to have positive attitude towards psychiatry throughout the posting. Results showed a statistically significant $(<0.01)$ positive attitude towards major areas in psychiatry except only psychiatric hospitals and treatment. Only 33 female interns chose psychiatry as a career choice after the posting of two weeks which is not statistically significant, while around $40 \%$ interns denied for it. Conclusion: Interns showed highly positive attitude towards psychiatry. The positive attitude of interns towards psychiatry would go a long way towards reducing the stigma attached to people with mental illness and mental health professionals.

Key words: Attitude; Career; Intern; Mental illness; Psychiatry

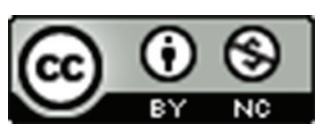

This work is licensed under a Creative Commons Attribution-NonCommercial 4.0 International License.

\section{INTRODUCTION}

Mental illness is a major public health problem which affects around $10 \%$ of the adults and $25 \%$ of people at some time during their lives. The occurrence and prevalence of mental illnesses are predicted to rise in coming years. The WHO has estimated that unipolar depression will rank first as the leading cause of disease burden around the globe by year $2030 .{ }^{1}$ Mental illnesses cause worldwide burden in terms of disability-adjusted life years (DALYs) and years lived with disability (YLD) mainly due to the stigmatisation, marginalisation and discrimination in the society. ${ }^{2}$

Even medical students, doctors, medical teachers and especially mental health professionals are not immune to social preconception, stigma and abhor remarks. ${ }^{3}$ 
They used to face these challenges in everyday practices. These factors contribute to negative attitude in health professionals. Customary negative attitude in the mental health professionals leads to great hindrance in providing mental health care to psychiatric patients. ${ }^{4}$ It also contributes to inattention to required mental health care needs, gratuitous referrals, indecent treatment and social support. ${ }^{5}$ Due to which very low number of medical students choose psychiatry as a career which contributes to the dearth of psychiatrists. ${ }^{6}$ In developed countries 12 psychiatrists per one lac people are available while India has 0.75 psychiatrists per one lac people but the desirable number is three psychiatrists per one lakh people. In India, out of 9000 psychiatrists only $15-20 \%$ are female which is very low as compared to other medicine disciplines where about $40-50 \%$ are female health professionals. ${ }^{7}$

Medical students are future care providers directly or indirectly. They, mainly interns, are the budding population stepping into the field of medical practice and bearing interest towards various specialities and illnesses. ${ }^{8,9}$ Attitude of intern towards psychiatry is determined by various factors like personality, past experiences like training in medicine and other specialities, social climate within medical colleges, and most importantly on the attitude of other teaching faculty members towards psychiatry which can be assessed during their posting in psychiatry. ${ }^{10}$

Their attitude towards psychiatry forms the stepping stone for making their decisions to pursue it as a career. This makes the attempt to study the current attitude of intern towards psychiatry and psychiatrists. These types of study might help in improving and making the positive attitude of the interns. Mental health professionals with positive attitude might help in reducing the stigma and discrimination across the globe in interns by changing their outlook. ${ }^{11}$ If positive attitude is built during their internship or training period, it may lead to more students opting for psychiatry as their career choice to fill the gap between high prevalence of mental illnesses and low availability of psychological treatment. ${ }^{12}$ So, in order to ensure the mental health and integration of people to get better treatment and referral timely, young and enthusiastic psychiatrists with positive attitude are needed. ${ }^{11}$

There are several Indian studies on the medical students or interns' attitude towards psychiatry. The novelty of this study is that this is the first of its kind being conducted to study the attitude towards psychiatry as well as psychiatry as a career choice in female interns only. It is needed in order to generate a greater interest in choosing this field for these young doctors and to overcome the shortage of female psychiatrists because they are noted to be more empathic in their approach and their patients report better satisfaction level as compared to their male counterparts. ${ }^{13}$

In view of the above-mentioned facts, this study aimed at studying the current attitude and aftermath of clinical posting in psychiatry on attitude of female interns towards psychiatry and estimated likelihood of psychiatry as a career choice among female intern.

\section{Aims and objectives}

To study and compare the current attitude and impact of psychiatry posting on attitude towards psychiatry in female interns.

To estimate the likelihood of Psychiatry as a career choice in female interns.

\section{MATERIALS AND METHODS}

\section{Ethical approval}

The study was initiated on the female interns in one of the tertiary care hospital in north India after getting through the Ethical Committee approval. Ethical consideration considered in concordance with the Helinski Declaration with the approval of the study from Ethical committee of our institution. A written informed consent form which explained the nature of study was obtained from all the interns prior to the study.

\section{Study design and setting}

It is a cross-sectional observational study in a women medical college in North India from January 2019 to December 2019. A total of 112 interns attending posting in psychiatry during their internship were included in the study. These interns have attended 2 weeks of clinical posting in $2^{\text {nd }}$ year and around 20 theory lectures on psychiatry during $3^{\text {rd }}$ year of their MBBS curriculum.

\section{Inclusion criteria}

Those interns who had not been exposed to psychiatry posting during their internship.

\section{Exclusion criteria}

Those interns whose relatives were psychiatrist, currently on treatment for any psychiatric disorders or having past and/or family history of psychiatric illness were excluded from the study.

\section{Procedure}

The purpose of the study was explained to the interns and written informed consent was taken. A self-assessable ATP-30 questionnaire was filled by the interns after studying it properly on the first day of their posting and after 15 days or on the last day of their posting in psychiatry department. We emphasised 
the confidentiality as names were not requested. Students were not allowed to discuss their answers among themselves to avoid the group influence. We emphasised anonymity to overcome the possible tendency of the students to give answers perceived as acceptable to the investigators rather than representative of the respondents' attitude. The responses on the Likert scale were grouped together for simplifying the analysis, for example, "strongly agree" and "agree" were combined into "agreed" response, and "strongly disagree" and "disagree" were combined into "disagreed" response.

\section{Tools}

\section{Attitude towards psychiatry (ATP) - 30 scale}

The 30 item standardized and structured questionnaire ATP-30 was developed by Burra and colleagues to study the attitude towards various aspects of psychiatry on the basis of a 5 - point Likert scale (1-strongly agree, 2-agree, 3-neutral, 4-disagree and 5-strongly disagree). This scale has multiple dimensions and measures, so this scale is divided into 4 groups containing similar questions clustering around a similar theme. These groups are- attitude towards psychiatric patients and illness, psychiatrists and psychiatry, psychiatric knowledge and teaching, psychiatric treatment and hospitals. Out of 30 items, 15 items are directed at the positive attitude and remaining 15 items at the negative attitude towards psychiatry. To calculate a sum score, scores of positively phrased items were subtracted from 6 resulting in higher values for a more positive attitude and finally item scores of positively and negatively phrased items were summed up. The sum score ranged between 30 and 150 points. The higher the score, more favourable the attitude. The sum score of 90 would represent the logical neutral point of the scale. The score below this logical neutral point or 90 , implies negative attitude and above 90 implies positive attitude towards psychiatry. The ATP-30 has shown good validity and reliability and has been used in various international and Indian studies with a Cronbach's alpha of $0.831 .{ }^{14}$

\section{Statistical analysis}

Descriptive data was analyzed by using mean and standard deviation. For continuous variables Student $t$-test was used for normally distributed data where $\mathrm{p}$ value $<0.05$ was taken as statistically significant. Data was analyzed using latest version of statistical software SPSS (21.0) Info.

\section{RESULTS}

Responses were obtained from 112 female interns, out of which 98 were considered for further analysis because 14 female interns fulfilled the exclusion criteria. 11 interns were currently under psychiatric treatment or having past/ family history of psychiatric illness and three interns had a relative or family member as a psychiatrist.
Attitude of the interns towards psychiatry on ATP-30 Scale was positive before posting in $95 \%$ interns and after posting in 97\% interns as shown in (Table 1).

The total ATP mean score after posting was higher than before the posting which was statistically significant ( $\mathrm{p}$ value $<0.001$ ) and score of positive domains was also statistically significant ( $\mathrm{p}$ value $<0.001$ ) as shown in (Table 2$)$.

Table 3 shows the mean, standard deviation and range of all the four groups of ATP-30 Scale before and after the posting. Attitude towards psychiatric patients and illness, psychiatry and psychiatrists, psychiatric knowledge and teaching shows statistically significant improvement except the attitude towards psychiatric hospitals and treatment after the posting of two weeks.

Eighteen interns chose psychiatry as a career of choice before the posting. After the posting, 33 female interns chose psychiatry as a career choice. But five interns dropped the idea of choosing psychiatry as a career choice after the posting who were "agreed" to it before posting. Forty-five interns were of "neutral" opinion before posting which changed to 24 interns choosing psychiatry as a career choice. Interns who "disagreed" in choosing psychiatry as a career choice increased from 35 to 41 after the posting as shown in (Table 3) under the statement "I would like to be a psychiatrist".

Most of the interns (65-97\%) were "agreed" with each statement in group 1. It was a statistically significant improvement in all the statements included under this group as shown in (Table 4 ).

Most of the statements were not statistically significant under the group 2, 3 and 4 except the three statements in group 2, two statements in group 3 and three statements in group 4 as shown in (Tables 5-7) respectively.

\section{DISCUSSION}

Attitude is a mature way of thinking or feeling about situations compelling people to respond in some manner as per their preferences. It has behavioral, affective and cognitive components. ${ }^{14}$ The present study is a

\begin{tabular}{|c|c|c|}
\hline Attitude & $\begin{array}{l}\text { Before posting } \\
\text { No. of interns (\%) }\end{array}$ & $\begin{array}{c}\text { After posting } \\
\text { No. of interns (\%) }\end{array}$ \\
\hline Positive attitude & 93 (95) & $95(97)$ \\
\hline Negative attitude & $5(5)$ & $3(3)$ \\
\hline Neutral attitude & -- & -- \\
\hline
\end{tabular}

Number and percentage of interns showing different types of attitude on ATP - 30 Scale 


\begin{tabular}{|c|c|c|c|c|c|c|c|}
\hline \multirow[t]{2}{*}{ Domains } & \multicolumn{2}{|c|}{ Mean } & \multicolumn{2}{|c|}{ SD } & \multicolumn{2}{|c|}{ Range } & \multirow[t]{2}{*}{ P value } \\
\hline & Before posting & After posting & Before posting & After posting & Before posting & After posting & \\
\hline ATP - 30 scale & 108.02 & 113.26 & 9.63 & 11.33 & $85-131$ & $82-136$ & $<0.001^{* *}$ \\
\hline Positive Domain & 56.48 & 60.21 & 5.41 & 5.96 & $42-70$ & 49-73 & $<0.001^{* *}$ \\
\hline Negative Domain & 51.69 & 53.28 & 5.76 & 8.19 & $32-67$ & $29-68$ & 0.110 \\
\hline
\end{tabular}

\begin{tabular}{|c|c|c|c|c|c|c|c|c|}
\hline \multirow[t]{2}{*}{ Sr.No. } & \multirow[t]{2}{*}{ Groups } & \multicolumn{2}{|c|}{ Mean } & \multicolumn{2}{|c|}{ SD } & \multicolumn{2}{|c|}{ Range } & \multirow[t]{2}{*}{$P$ value } \\
\hline & & $\begin{array}{l}\text { Before } \\
\text { posting }\end{array}$ & $\begin{array}{c}\text { After } \\
\text { posting }\end{array}$ & $\begin{array}{l}\text { Before } \\
\text { posting }\end{array}$ & $\begin{array}{c}\text { After } \\
\text { posting }\end{array}$ & $\begin{array}{l}\text { Before } \\
\text { posting }\end{array}$ & $\begin{array}{c}\text { After } \\
\text { posting }\end{array}$ & \\
\hline 1. & Attitude towards psychiatric patients and illness & 16.34 & 17.56 & 1.92 & 2.20 & $11-20$ & $13-20$ & $0.001^{* *}$ \\
\hline 2. & Attitude towards psychiatry and psychiatrists & 37.92 & 39.49 & 4.34 & 5.34 & $26-49$ & $27-52$ & $0.015^{\star *}$ \\
\hline 3. & Attitude towards psychiatric knowledge and teaching & 23.95 & 25.51 & 3.46 & 3.61 & $20-36$ & $18-40$ & 0.003 ** \\
\hline 4. & Attitude towards psychiatric hospitals and treatment & 29.65 & 30.43 & 3.13 & 3.98 & $17-34$ & $18-35$ & 0.155 \\
\hline
\end{tabular}

\begin{tabular}{|c|c|c|c|c|c|c|c|}
\hline Sr.No. & Statements & Postings & $\begin{array}{c}\text { Agreed } \\
\text { (No. of interns) }\end{array}$ & $\begin{array}{c}\text { Rest (neutral + } \\
\text { disagreed) (No. of Interns) }\end{array}$ & Mean & SD & P-value \\
\hline \multirow[t]{2}{*}{1} & \multirow{2}{*}{$\begin{array}{l}\text { If we listen to them patients are just } \\
\text { as humans as other people. }\end{array}$} & Before Posting & 84 & $14(12+2)$ & 4.23 & 0.79 & $0.001^{* *}$ \\
\hline & & After Posting & 93 & $5(4+1)$ & 4.60 & 0.62 & \\
\hline \multirow[t]{2}{*}{2} & \multirow{2}{*}{$\begin{array}{l}\text { Psychiatric illness deserves at least } \\
\text { as much attention as physical illness }\end{array}$} & Before Posting & 93 & $5(2+3)$ & 4.52 & 0.74 & $0.034^{* *}$ \\
\hline & & After Posting & 97 & $1(0+1)$ & 4.71 & 0.51 & \\
\hline \multirow[t]{2}{*}{3} & \multirow{2}{*}{$\begin{array}{l}\text { Psychiatric patients are more often } \\
\text { interesting to work with than other } \\
\text { patients }\end{array}$} & Before Posting & 51 & $47(37+10)$ & 3.58 & 0.94 & $0.007^{\star *}$ \\
\hline & & After Posting & 66 & $32(24+8)$ & 3.97 & 0.97 & \\
\hline \multirow[t]{2}{*}{4} & \multirow{2}{*}{$\begin{array}{l}\text { It is interesting to try unravel the } \\
\text { cause of psychiatric illness }\end{array}$} & Before Posting & 75 & $23(19+4)$ & 4.00 & 0.79 & $0.019^{* *}$ \\
\hline & & After Posting & 85 & $13(10+3)$ & 4.28 & 0.78 & \\
\hline
\end{tabular}

Comparison of each statement under group psychiatric patients and illness in terms of their responses (agreed and rest) along with their mean, standard deviation (SD) and $p$ value (significant $<0.05$ represented by $* *$ ). All statements are under positive domain

modest attempt at assessing the current attitude and aftermath of 2 weeks' clinical posting of female interns in psychiatry. Exposure of interns during the posting includes the supervised assessment of the patients under the consultants/residents, involvement in the management and clinical discussions during ward rounds and one seminar by each intern during their postings.

Attitude of the interns did not change much after the clinical posting in psychiatry as most of the interns $(>95 \%)$ had positive attitude towards psychiatry itself throughout the posting. It was highly surprising to us that no interns had an overall negative attitude towards psychiatry. Positive attitude was also observed in some previous studies ${ }^{3,9,15-18}$ where $48 \%$ to $88 \%$ female interns showed positive attitude. Few studies ${ }^{19-21}$ revealed have revealed that $9 \%$ to $65 \%$ interns showed negative attitude towards psychiatry after the posting, which is contrary to the present study where we did not observe any blantly negative attitude. Mean standard deviation score in our study was very high as compared to a study done by
Jilowa et $\mathrm{al}^{18}$ and other studies. ${ }^{10,22}$ Attitude of the interns increased significantly on the positive domain of ATP30 Scale $(p<0.001)$. However, the attitude of the intern improved even on the negative domains but it was not statistically significant. These findings were consistent with studies done in last few years. ${ }^{22,23,24}$ On comparison of the ATP-30 scale's four groups, it was found that attitude of the interns in three groups towards psychiatry significantly (statistically) increased after the posting of 15 days except the attitude towards psychiatric hospitals and treatment. Our findings were much better than a study done by Sarhan et $\mathrm{al}^{23}$ in which attitude towards only psychiatric patients and illness, and psychiatry and psychiatrists were statistically significant.

This highly positive attitude even at the beginning of the posting may be because of interns think that psychiatry as a discipline of medicine is of prime importance in the current stressful era and the psychiatric illnesses run rampant across the globe. Main reason behind the positive attitude of the interns in our study were the well-established 


\begin{tabular}{|c|c|c|c|c|c|c|c|}
\hline Sr.No & Statements & Postings & $\begin{array}{c}\text { Agreed } \\
\text { (No. of interns) }\end{array}$ & $\begin{array}{l}\text { Rest(neutral +disagreed) } \\
\text { (No. of Interns) }\end{array}$ & Mean & SD & P-value \\
\hline \multirow[t]{2}{*}{1} & \multirow{2}{*}{$\begin{array}{l}\text { Psychiatrists talk a lot but do very } \\
\text { little. }^{\dagger}\end{array}$} & Before Posting & 19 & $79(26+53)$ & 3.42 & 1.04 & \multirow[t]{2}{*}{$0.012^{* *}$} \\
\hline & & After Posting & 12 & $86(16+70)$ & 3.79 & 0.95 & \\
\hline \multirow[t]{2}{*}{2} & \multirow{2}{*}{$\begin{array}{l}\text { Psychiatrists seem to talk nothing but } \\
\text { sex. }^{\dagger}\end{array}$} & Before Posting & 1 & $97(14+83)$ & 4.19 & 0.69 & \multirow[t]{2}{*}{$0.040^{* *}$} \\
\hline & & After Posting & 2 & $96(4+92)$ & 4.41 & 0.76 & \\
\hline \multirow[t]{2}{*}{3} & \multirow{2}{*}{$\begin{array}{l}\text { At times it's hard to think of psychiatrists } \\
\text { as equal to other doctors. }{ }^{\dagger}\end{array}$} & Before Posting & 15 & $83(18+65)$ & 3.63 & 1.14 & \multirow[t]{2}{*}{0.268} \\
\hline & & After Posting & 13 & $85(21+64)$ & 3.83 & 1.23 & \\
\hline \multirow[t]{2}{*}{4} & \multirow[t]{2}{*}{ I would like to be a psychiatrist." } & Before Posting & 18 & $80(45+35)$ & 2.85 & 0.89 & \multirow[t]{2}{*}{0.544} \\
\hline & & After Posting & 33 & $65(24+41)$ & 2.94 & 1.23 & \\
\hline \multirow[t]{2}{*}{5} & \multirow{2}{*}{$\begin{array}{l}\text { Psychiatrists tend to be least as stable } \\
\text { as average doctors. }{ }^{\dagger}\end{array}$} & Before Posting & 56 & $42(24+18)$ & 2.58 & 0.93 & \multirow[t]{2}{*}{0.158} \\
\hline & & After Posting & 64 & $34(17+17)$ & 2.38 & 1.16 & \\
\hline \multirow[t]{2}{*}{6} & \multirow{2}{*}{$\begin{array}{l}\text { Psychiatrists get less satisfaction from } \\
\text { their work than other specialists. }{ }^{\dagger}\end{array}$} & Before Posting & 13 & $85(39+46)$ & 3.44 & 0.86 & \multirow[t]{2}{*}{0.277} \\
\hline & & After Posting & 10 & $88(24+64)$ & 3.59 & 1.10 & \\
\hline \multirow[t]{2}{*}{7} & \multirow{2}{*}{$\begin{array}{l}\text { If I were asked what I considered to } \\
\text { be three most exciting specialties, } \\
\text { psychiatry would be excluded. }{ }^{\dagger}\end{array}$} & Before Posting & 38 & $60(16+44)$ & 3.03 & 1.15 & \multirow[t]{2}{*}{0.106} \\
\hline & & After Posting & 30 & $68(19+49)$ & 3.30 & 1.16 & \\
\hline \multirow[t]{2}{*}{8} & \multirow{2}{*}{$\begin{array}{l}\text { Practice of psychiatry allowsthe } \\
\text { development of really rewarding } \\
\text { relationship with people.\# }\end{array}$} & Before Posting & 69 & $29(25+4)$ & 3.91 & 0.76 & \multirow[t]{2}{*}{0.929} \\
\hline & & After Posting & 79 & $19(14+5)$ & 3.90 & 0.81 & \\
\hline \multirow[t]{2}{*}{9} & \multirow{2}{*}{$\begin{array}{l}\text { Psychiatry is unappealing because it } \\
\text { makes so little use } \\
\text { of medical training. }^{\dagger}\end{array}$} & Before Posting & 18 & $80(20+60)$ & 3.52 & 0.94 & \multirow[t]{2}{*}{0.230} \\
\hline & & After Posting & 13 & $85(19+66)$ & 3.69 & 0.92 & \\
\hline \multirow[t]{2}{*}{10} & \multirow{2}{*}{$\begin{array}{l}\text { Psychiatry is a respected branch of } \\
\text { medicine." }\end{array}$} & Before Posting & 71 & $27(18+9)$ & 3.91 & 0.95 & \multirow[t]{2}{*}{$0.032^{* *}$} \\
\hline & & After Posting & 84 & $14(10+4)$ & 4.17 & 0.76 & \\
\hline \multirow[t]{2}{*}{11} & People taking up psychiatry are & Before Posting & 66 & $32(21+11)$ & 2.48 & 0.86 & \multirow[t]{2}{*}{0.186} \\
\hline & $\begin{array}{l}\text { running away from participation in real } \\
\text { medicine. }{ }^{\dagger}\end{array}$ & After Posting & 54 & $44(28+16)$ & 2.32 & 1.08 & \\
\hline
\end{tabular}

Comparison of each statement under group psychiatry and psychiatrists in terms of their responses (agreed and rest) along with their mean, standard deviation (SD) and p value (significant $<0.05$ represented by $* *)$. $(*)$ represents the statements under the positive domain. $(+)$ represents the statements under the negative domain

\begin{tabular}{|c|c|c|c|c|c|c|c|}
\hline Sr.No. & Statements & Postings & $\begin{array}{c}\text { Agreed } \\
\text { (No. of interns) }\end{array}$ & $\begin{array}{l}\text { Rest (neutral+ disagreed) } \\
\text { (No. of Interns) }\end{array}$ & Mean & SD & P-value \\
\hline \multirow[t]{2}{*}{1} & \multirow{2}{*}{$\begin{array}{l}\text { Most of the so-called facts in } \\
\text { psychiatry are really just vague } \\
\text { speculations. }^{\dagger}\end{array}$} & Before Posting & 17 & $81(28+53)$ & 3.41 & 0.88 & 0.302 \\
\hline & & After Posting & 18 & $80(20+60)$ & 3.55 & 0.99 & \\
\hline \multirow[t]{2}{*}{2} & \multirow{2}{*}{$\begin{array}{l}\text { Psychiatry has very little scientific } \\
\text { information to go on. }{ }^{\dagger}\end{array}$} & Before Posting & 16 & $82(23+59)$ & 3.55 & 0.92 & 0.530 \\
\hline & & After Posting & 13 & $85(23+62)$ & 3.63 & 0.89 & \\
\hline \multirow[t]{2}{*}{3} & \multirow{2}{*}{$\begin{array}{l}\text { It is so unscientific that even the } \\
\text { psychiatristscan't agree as to what } \\
\text { its basic applied science are. }{ }^{\dagger}\end{array}$} & Before Posting & 8 & $90(29+61)$ & 3.67 & 0.85 & 0.073 \\
\hline & & After Posting & 7 & $91(19+72)$ & 3.89 & 0.83 & \\
\hline \multirow[t]{2}{*}{4} & \multirow{2}{*}{$\begin{array}{l}\text { Psychiatric teaching increases } \\
\text { our under-standing of medical \& } \\
\text { surgical patients.\# }\end{array}$} & Before Posting & 42 & $56(32+24)$ & 3.22 & 0.99 & $0.001^{* *}$ \\
\hline & & After Posting & 57 & $41(30+11)$ & 3.71 & 0.91 & \\
\hline \multirow[t]{2}{*}{5} & \multirow{2}{*}{$\begin{array}{l}\text { These days psychiatry is most } \\
\text { important part of curriculum in } \\
\text { medical school. }\end{array}$} & Before Posting & 65 & $33(19+14)$ & 3.71 & 0.91 & 0.078 \\
\hline & & After Posting & 73 & $25(16+9)$ & 3.94 & 0.94 & \\
\hline \multirow[t]{2}{*}{6} & \multirow{2}{*}{$\begin{array}{l}\text { Majority of students report that their } \\
\text { undergraduate training has been } \\
\text { valuable.\# }\end{array}$} & Before Posting & 46 & $52(31+21)$ & 3.33 & 0.89 & $0.001^{* *}$ \\
\hline & & After Posting & 58 & $40(26+14)$ & 3.77 & 0.98 & \\
\hline \multirow[t]{2}{*}{7} & \multirow{2}{*}{$\begin{array}{l}\text { Psychiatry is so amorphous that it } \\
\text { cannot taught effectively. }{ }^{\dagger}\end{array}$} & Before Posting & 30 & $68(33+35)$ & 3.05 & 0.89 & 0.847 \\
\hline & & After Posting & 35 & $63(31+32)$ & 3.02 & 1.10 & \\
\hline
\end{tabular}

Comparison of each statement under group psychiatric knowledge and teaching in terms of their responses (agreed and rest) along with their mean, standard deviation (SD) and p value (significant $<0.05$ represented by **). $\left(^{\#)}\right.$ represents the statements under the positive domain. $\left(^{\dagger}\right)$ represents the statements under the negative domain

department of psychiatry, community based mental health programmes and well-organized celebrations of every particular day related to mental health and the participation of interns during their under-graduation in our institution. Interns attended their UG psychiatry lectures and clinical postings with more than $60 \%$ attendance which has helped in enhancement of their general awareness and attitude towards psychiatry. This positive attitude is essential for ensuring better care for patients as well as reduction of stigma for psychiatric disorders. 


\begin{tabular}{|c|c|c|c|c|c|c|c|}
\hline Sr.No. & Statements & Postings & $\begin{array}{l}\text { Agree } \\
\text { (No. of } \\
\text { interns) }\end{array}$ & $\begin{array}{c}\text { Rest (neutral + } \\
\text { disagreed) (No. of Interns) }\end{array}$ & Mean & SD & P-value \\
\hline \multirow[t]{2}{*}{1} & \multirow{2}{*}{$\begin{array}{l}\text { It is quite easy for me to accept the } \\
\text { efficacy of psychotherapy }\end{array}$} & Before Posting & 52 & $46(35+11)$ & 3.48 & 0.92 & $0.008^{* *}$ \\
\hline & & After Posting & 71 & $27(19+8)$ & 3.82 & 0.81 & \\
\hline \multirow[t]{2}{*}{2} & \multirow{2}{*}{$\begin{array}{l}\text { Practice of psychotherapy basically } \\
\text { fraudulent since there is no strong } \\
\text { evidence that it is effective }{ }^{+}\end{array}$} & Before Posting & 14 & $84(30+54)$ & 3.46 & 0.87 & 0.233 \\
\hline & & After Posting & 10 & $88(24+64)$ & 3.61 & 0.85 & \\
\hline \multirow[t]{2}{*}{3} & \multirow{2}{*}{$\begin{array}{l}\text { With the forms of therapy now at hand, } \\
\text { most psychiatric patients improve }\end{array}$} & Before Posting & 70 & $28(24+4)$ & 3.77 & 0.70 & $0.010^{* *}$ \\
\hline & & After Posting & 84 & $14(12+2)$ & 4.04 & 0.68 & \\
\hline \multirow[t]{2}{*}{4} & \multirow{2}{*}{$\begin{array}{l}\text { Psychiatric treatment causes patients to } \\
\text { worry too much about symptoms. }{ }^{\dagger}\end{array}$} & Before Posting & 32 & $66(29+37)$ & 3.09 & 0.88 & 0.886 \\
\hline & & After Posting & 35 & $63(26+37)$ & 3.11 & 1.04 & \\
\hline \multirow[t]{2}{*}{5} & \multirow{2}{*}{$\begin{array}{l}\text { There is very little that psychiatrists can } \\
\text { do for their patients. }{ }^{\dagger}\end{array}$} & Before Posting & 10 & $88(9+79)$ & 3.86 & 0.76 & 0.942 \\
\hline & & After Posting & 15 & $83(9+74)$ & 3.85 & 1.06 & \\
\hline \multirow[t]{2}{*}{6} & \multirow{2}{*}{$\begin{array}{l}\text { In recent years, psychiatric treatment has } \\
\text { become quite effective }\end{array}$} & Before Posting & 87 & $11(8+3)$ & 4.08 & 0.58 & $0.026^{* *}$ \\
\hline & & After Posting & 92 & $6(5+1)$ & 4.29 & 0.61 & \\
\hline \multirow[t]{2}{*}{7} & \multirow{2}{*}{$\begin{array}{l}\text { Psychiatric hospitals little more than } \\
\text { prisons. }^{\dagger}\end{array}$} & Before Posting & 12 & $86(14+72)$ & 3.79 & 0.89 & 0.341 \\
\hline & & After Posting & 16 & $82(19+63)$ & 3.64 & 1.14 & \\
\hline \multirow[t]{2}{*}{8} & \multirow{2}{*}{$\begin{array}{l}\text { Psychiatric hospitals have specific } \\
\text { contribution to make to the treatment of } \\
\text { mentally ill. }\end{array}$} & Before Posting & 86 & $12(9+3)$ & 4.13 & 0.71 & 0.624 \\
\hline & & After Posting & 81 & $17(11+6)$ & 4.07 & 0.96 & \\
\hline
\end{tabular}

Comparison of each statement under group psychiatric hospitals and treatment in terms of their responses (agreed and rest) along with their mean, standard deviation (SD) and p value (significant $<0.05$ represented by **). $\left(^{\#}\right)$ represents the statements under the positive domain. $\left(^{\dagger}\right)$ represents the statements under the negative domain

\section{Group 1 (Attitude towards psychiatric patients and illness)}

Table 4 shows the responses to the statements that represent the attitude towards psychiatric patients and illnesses which were statistically significant after the posting. $67-97 \%$ of the interns were "agreed" to all the statements after the posting which depict positive attitude towards psychiatric patients and illnesses. They agreed that psychiatric patients are not only human but they are also interesting and need great attention. Only 3-33\% interns expressed discriminatory views about psychiatric patients and illnesses following the completion of posting. Similar results were shown by previous studies. ${ }^{10,18} \mathrm{~A}$ few studies revealed that only one or two statements show positive attitude and others were neutral to negative. ${ }^{23,25,26}$ This great improvement in attitude towards psychiatric patients and illnesses after the training has been found explained by coming in contact with psychiatric patients while history-taking and their involvement in patients' care, which led to the interns feeling comfortable and increasingly confident in interviewing the patients. ${ }^{15}$ These types of approaches towards psychiatric patients and illnesses among interns were the key factors in determining the positive attitude in our study.

\section{Group 2 (Attitude towards psychiatry and psychiatrists)}

Table 5 shows that $55-98 \%$ of the interns gave favorable responses to the statements that represent their overall positive attitude towards psychiatry and psychiatrists after the posting.

Eight out of 11 statements showed positive attitude except the three like "Psychiatrists tend to be least stable as average doctors" (66\% were "agreed" and think that psychiatrists are not as emotionally stable as average doctors and they are nearly similar to their patients), "I would like to be a psychiatrist" (66\% were "disagreed") and "People taking up psychiatry are running away from participation in real medicine" (55\% were "agreed" and think that psychiatry is not real medicine due to the absence of strong evidence). Similar results in the past where $45-80 \%$ of the interns showed positive attitude. $8,10,18,22$ Some studies revealed negative attitude of interns towards psychiatry and psychiatrists. ${ }^{20,23,25}$ Viewing psychiatry as an advancing field along with great break-throughs in the last few years, students are maintaining a highly positive attitude towards psychiatry in this study.

\section{Group 3 (Attitude towards psychiatry knowledge and teaching)}

Table 6 shows the responses to the statements that represent the overall positive attitude of interns towards psychiatric knowledge and teaching. Most of the statements' response improved but were not statistically significant after the posting, except for these - Psychiatric teaching increases our understanding of medical \& surgical patients" and "Majority of students report that their undergraduate training has been valuable" ( $<<0.001) .80-90 \%$ interns think that psychiatry has scientific discipline and not just vague hypothesis. After the completion of posting, most of the interns expressed more accurate beliefs about the etiology of psychiatric disorders. Up to $75 \%$ interns think that psychiatry was the most important part of curriculum during their undergraduate training, it was valuable and their psychiatric teaching helps in understanding other patients. Only One facet that shows decline in attitude is, 
"Psychiatry is so amorphous that it cannot be taught effectively." Similar results were also found by some previous studies. $8,10,18,22$ Some studies revealed a negative attitude of interns towards psychiatric knowledge and teaching., ${ }^{23,25,27}$ These findings came as a great surprise because psychiatric knowledge ameliorated along the course and psychiatric postings. During the posting, involvement of interns in psychiatric consultation played a pivotal role in their understanding the role of psychiatry in medical and surgical patients. Involving medical students and interns in the study itself generated curiosity and awareness among them towards academic research in general and psychiatry in particular. Demonstration of psychopathology to learn the required skills during the psychiatry posting also played a greater role to enhance the psychiatric knowledge. Interns think that psychiatry is structurally ambiguous might be due to lower number of psychiatry lectures during their MBBS curriculum. Psychiatry internship is not enough to understand the specialty completely. We must build and maintain a strong and sophisticated curriculum throughout the MBBS course. These findings demand to make the attendance compulsory and an independent examination subject so that students may be more attentive and have better understanding of the subject.

\section{Group 4 (Attitude towards psychiatry hospitals and treatment)}

Table 7 shows the responses to the statements that represent the overall positive attitude of interns towards psychiatric hospitals and treatment. $86 \%$ interns believed that there is a certain role of psychiatric hospitals in the treatment of mentally ill patients and these hospitals are not like prisons. Around $92 \%$ interns agreed that psychiatric treatment has become quite effective in recent years. $72-88 \%$ interns responded in the favor of psychotherapy. Only $10 \%$ were of the opinion that psychotherapy is fraudulent rather than evidence based. Generally positive attitude ( $89 \%$ agreed) was observed regarding the psychiatrists' ability to help their patients. Most of the statements' responses improved but were not statistically significant after the posting except, "It is quite easy for me to accept the efficacy of psychotherapy", "With the forms of therapy now at hand, most psychiatric patients improve", and "In recent years, psychiatric treatment has become quite effective" ( $p<0.002) .35 \%$ of the interns were "agreed" that psychiatric treatment causes patients to worry too much about symptoms. Similar results where interns showed positive attitude were also found in studies done in past. ${ }^{3,8,10,18}$ Some studies ${ }^{23,25}$ revealed a negative attitude of interns towards psychiatric hospitals and treatments. After the posting, most of the interns expressed better appreciation of therapeutic intervention might be due to their involvement in patients' work up and ward rounds. They observed that patients have shown improvement with newer antipsychotics and antidepressants with fewer side effect profiles which resulted in the positive attitude of interns towards psychiatric hospitals and treatment.
Interns were more worried about the symptoms or illnesses due to frequent relapse and chronic course of treatment in psychiatric illnesses. High quality teaching and posting containing a variety of clinical experiences including the explanation of nature, prognosis and treatment of psychiatric illnesses, bedside teaching, problem-based learning, should be included in the curriculum to improve their attitude towards psychiatric hospitals and treatment. ${ }^{3,28}$ During the training in psychiatry, students might spend more time at mental health clinic so that they can see the improvement with treatment and better prognosis of patient. These types of approaches could be promising in improving the attitude of the interns towards psychiatric hospitals and treatment.

\section{Psychiatry as a career choice}

Only 33 (34\%) female interns chose psychiatry as a career choice and 41 interns were "disagreed" in choosing psychiatry as a career choice after the posting of 15 days. There was an almost $15 \%$ surge in interns agreeing to think about being a psychiatrist in future, after the posting. There was not a significant improvement on the level of interest in psychiatry as a career choice $(p=0.544)$. Similar results in previous studies were found where $25-50 \%$ interns were ready to choose psychiatry as a career choice after the posting. . $10,17,18,29^{2}$ In only two recent studies ${ }^{8,18}$ where $60-70 \%$ of the interns were ready to choose and less than $10 \%$ were "disagreed" in choosing psychiatry as a career choice and improvement was statistically significant. Evidence of the aftermath of posting on career preferences is mixed, with some studies ${ }^{30}$ finding increase in the interest of being a psychiatrist after the posting and other findings no difference. ${ }^{31}$

Despite the highly positive attitude of the interns towards psychiatry, a disparity was found between high interest in psychiatry and low preference to psychiatry as a career choice in the present study. We may set out various reasons for this disparity. Several factors demoralize the interns in pursuing psychiatry, like the perception of it not being a real medicine, imprecise and unscientific. There is also a belief that psychiatrists are emotionally not stable, more vulnerable to develop psychiatric disorders, do nothing more than prescribing sedatives and tranquilizers etc.

Note that some responses had to be handwritten and were not a part of any scale used. Interns think that psychiatry faces challenges like questionable validity of diagnosis, the opposing beliefs of psychiatrists, the unclear role of psychiatrists and financial prospects. Interns felt uncomfortable with patients, had poor prognosis and they felt that interacting with them is stressful, dangerous, emotionally draining, disturbing and overwhelming. 50$60 \%$ interns were interested in other specialties. Psychiatry as a career was ranked after medicine, surgery and pediatrics because of low prestige or lower image among society. 
Interns think that there is need of great patience, skills and higher intellectual challenges to become a psychiatrists. A possible explanation regarding the dissonance could be the firm and pervasive stigma attached to mental disorders. Interns think that psychiatrists are often subjected to ridiculous stereotypic and stigmatizing comments and remarks from non-psychiatrist medical professionals, from their friends and family members and from society.

\section{Limitations of the study}

Like any other study, there are limitations of the present study like, it is a cross-sectional study and the sample size was small. The study was limited to only one medical college, so the findings cannot be generalised to other areas. We concluded that posting improves the attitude towards psychiatry, but we cannot predict that their views will remain constant as students' progress through the course. The study's participants were aware of our area of interest, which could have influenced some of the responses.

\section{CONCLUSION}

The attitude of the interns was highly positive during the clinical posting in psychiatry which improved significantly after the posting. Our study supports the hypothesis that as the exposure to psychiatry increases, the attitude towards psychiatry improves and the interns' consideration of psychiatry as a career increase. Interns showed some interest in choosing psychiatry as a future career option. Our study depicted that even after the posting; there were lesser number of interns who chose psychiatry as a career option. So, it has been felt that psychiatry remains a neglected subject during the under graduation.

\section{Future suggestions}

There is a need to modify the psychiatry curriculum and there should be a requirement of fully integrated teaching during under graduate (UG) training to develop more interest in the psychiatry discipline itself. So, we need to dive deep so as to understand the relationship between various factors like classroom teaching, clinical rotation, association of interns with consultants/residents and the importance of good role models which we feel might be useful in transforming the positive attitude into serious consideration of psychiatry as a career choice.

\section{REFERENCES}

1. Kessler RC, Gaxiola SA, Alonso J, Chatterji S, Lee S and Ormel J. The global burden of mental disorders: An update from the WHO World Mental Health (WMH) surveys. Epidemiol Psychiatr Soc. 2009; 18(1):23-33.

https://doi.org/10.1017/S1121189X00001421

2. Whiteford HA, Degenhardt L, Rehm J, Baxter AJ, Ferrari AJ,
Erskine HE, et al. Global burden of disease attributable to mental and substance use disorders: findings from the the global burden of disease study 2010. The Lancet 2013;382:1575-1586. https://doi.org/10.1016/S0140-6736(13)61611-6

3. Jilowa RC, Meena PS, Jain M, Dhanda G, Sharma KK, Kumawat AK, et al. Attitude of undergraduate medical students towards psychiatry: a cross sectional comparative study. Ind Psychiatry Journal. 2018; 27:124-130. https://doi.org/10.4103/ipj.ipj_82_17

4. Khan SA, Yousafzai AU, Mehir RK and Inam-ul-Haq. Attitude of medical students towards psychiatry in NWFP. J Ayub Med Coll Abbottabad. 2008; 20:44-46.

5. Kishore J, Gupta A, Jiloha RC and Bantman P. Myths, beliefs and perceptions about mental disorders and health-seeking behaviour in Delhi, India. Indian J Psychiatry 2011; 53:324-329. https://doi.org/10.4103/0019-5545.91906

6. Katschnig $\mathrm{H}$. Are psychiatrists an endangered species? Observations on internal and external challenges to the profession. World Psychiatry. 2010; 9:21-28. https://doi.org/10.1002/j.2051-5545.2010.tb00257.x

7. Garg K, Kumar NC and Chandra PS. Number of psychiatrists in India: Baby steps forward, but a long way to go. Indian J Psychiatry. 2019; 61:104-105.

https://doi.org/10.4103/psychiatry.IndianJPsychiatry_7_18

8. Desai ND and Chavda PD. Attitudes of undergraduate medical students towards mental illnesses and psychiatry. J Edu Health Promot 2018; 7:50-56.

https://doi.org/10.4103/jeph.jeph_87_17

9. Hemanth Kumar BG, Keertish N, Sathyanarayana MT and Hyder S. Attitude of interns towards psychiatry before and after 2 weeks of clinical rotation. Indian J Soc Psychiatry. 2017; 33:365-369. https://doi.org/10.4103/0971-9962.218598

10. Mutalik NR, Tejaswi TP, Kashinakunti M and Chaudhari SB. Attitude of medical undergraduate and postgraduate students towards psychiatry: a cross sectional study. Open J Psychiatry Allied Sci. 2017; 9:3-9. https://doi.org/10.5958/2394-2061.2018.00001.0

11. Roberts LW and Bandstra BS. Addressing stigma to strengthen psychiatric education. Acad Psychiatry 2012; 36:347-350. https://doi.org/10.1176/appi.ap.12060118

12. Ramamurthy C, Srikumar PS, Joshua E and Rasamy G. Impact of psychiatry training on attitude of undergraduate medical students. Malays J Psychiatry. 2008; 17:1-8.

13. Roter DL, Hall JA and Hoki Y. Physicians gender effects in medical communication: a meta analytic review. JAMA. 2002; 288(6):755-764.

https://doi.org/10.1001/jama.288.6.756

14. Burra P, Kalin R, Leichner PWJJ, Waldron JJ, Handforth JR, Jarett FJ, et al. The ATP 30- a scale for measuring attitude of medical students. Med Educ. 1982; 16:31-38.

https://doi.org/10.1111/j.1365-2923.1982.tb01216.x

15. Lyons $Z$ and Janca A. Impact of psychiatry clerkship on stigma, attitudes towards psychiatry, and psychiatry as a career choice. BMC Med Educ. 2015; 15:34.

https://doi.org/10.1186/s12909-015-0307-4

16. Prasad KN, Sanjeev Kumar PB, Narayanankutty OK, Abraham A, Raj Z, Mandanagopal V, et al. "Why not psychiatry??" Interns of a medical college in Northern Kerala responds. Indian J Psychiatry. 2016; 58:204-207. https://doi.org/10.4103/0019-5545.183785

17. Warnke I, Gamma A, Buadze M, Schleifer R, Canela C, 
Strebel B, et al. Predicting medical students' current attitudes towards psychiatry, interest in psychiatry, and estimated likelihood of working in psychiatry: A cross sectional study in four European countries. Front Psychiatry. 2018; 9:49.

https://doi.org/10.3389/fpsyt.2018.00049

18. Jilowa CS, Chandarvanshi G, Mahawar B and Jain M. Impact of psychiatry training on attitude of medical students towards mental illness and psychiatry. IOSR J Dent Med Sci. 2016; 15:18-22.

https://doi.org/10.9790/0853-1504121822

19. Yadav T, Arya K, Kataria D and Balhara YPS. Impact of psychiatric education and training on attitude of medical students towards mentally ill. Ind Psychiatry J. 2012; 21:22-31. https://doi.org/10.4103/0972-6748.110944

20. Gulati P, Das S and Chavan BS. Impact of psychiatry training on attitude of medical students towards mental illness and psychiatry. Indian J Psychiatry. 2014; 56:271-277. https://doi.org/10.4103/0019-5545.140640

21. Lingeswaran A. Psychiatric curriculum and its impact on the attitude of Indian undergraduate medical students and interns. Indian J Psychol Med 2010; 32:119-127.

https://doi.org/10.4103/0253-7176.78509

22. Desai R, Panchal B, Vala A, Ratnani IJ, Vadher S and Khania P. Impact of clinical posting in psychiatry on the attitudes towards psychiatry and mental illness in undergraduate medical students. Gen Psychiatry. 2019; 32(3):e100072.

https://doi.org/10.1136/gpsych-2019-100072

23. Sarhan A, Alkhiri A, Maqadmi A, Alhazmi M and Bahuwyrith $M$. Medical students attitude toward psychiatry in Umm Al-Qura University : A Cross-sectional study. Int J Adv Res. 2017; 5:13591368.

https://dx.doi.org/10.21474/IJAR01/3292

24. Connaughton J and Gibson W. Physiotherapy students' attitude toward psychiatry and mental health: A cross sectional study. Physiother Can. 2016; 68:172-178.
https://doi.org/10.3138/ptc.2015-18E

25. Parikh NC, Sharma PS, Chaudhary PJ, Gandhi HA and Banwari GH. Study of attitude of interns towards psychiatry: A survey of a tertiary level hospital in Ahmedabad. Ind Psychiatry J. $2014 ;$ 23:143-148.

https://doi.org/10.4103/0972-6748.151690

26. Aruna G, Mittal S, Yadiyal MB, Acharya S, Acharya C and Uppulari C. Perception, knowledge and attitude toward mental disorders and psychiatry among medical undergraduates in Karnatka: A cross-sectional study. Indian J Psychiatry. 2016; 58:70-76.

https://doi.org/10.4103/0019-5545.174381

27. Feifel D, Moutier CY and Swerdlow NR. Attitudes toward psychiatry as a prospective career among students entering medical school. Am J Psychiatry. 2014; 9:1397-1402. https://doi.org/10.1176/ajp.156.9.1397

28. Nayak A. Changing medical students' attitudes towards psychiatry through newer teaching techniques. Mens Sana Monogr. 2015; 13:180-186. https://doi.org/10.4103/0973-1229.153338

29. Mortlock AM, Puzzo I, Taylor S, Kumari V, Young S, Sengupta S, et al. Enrichment activities in the medical schools psychiatry programme - could this be a key to engaging medical students in psychiatry? A study from a high secure forensic psychiatric hospital. BMC Psychiatry. 2017; 17(1):83. https://doi.org/10.1186/s12888-017-1236-z

30. Rodrigo A, Wijesinghe $\mathrm{C}$ and Kuruppuarachchi K. Changes in the attitude towards psychiatry with introduction of a new curriculum: experiences of a Sri Lankan Medical school. SL J Psychiatry. 2012; 3:14-16. https://doi.org/10.4038/sljpsyc.v3i1.4454

31. Gazdag G, Zsargo E, Vukov P, Ungvari GS and Tolna J. Change of medical students attitudes towards psychiatry: the impact of psychiatric clerkship. Psychiatr Hung. 2009; 24:248-254.

\footnotetext{
Author's contributions:

SG-Concept and design of the study, Interpreted the results, Manuscript preparation and Critical revision of manuscript; AC-Literature review, helped in preparation of first draft of manuscript; MS- Critical revision of manuscript; MK- Collection, compilation and interpretation of data; SS- Statistically analyzed the data; KB- Revision of the manuscript and English grammar correction.

Work attributed to:

Department of Psychiatry, Bhagat Phool Singh Government Medical College For Women, Khanpur Kalan, Sonipat, Haryana, India.

Orcid ID:

Dr. Sunny Garg - (1) https://orcid.org/0000-0002-5979-0241

Dr. Alka Chauhan - (1) https://orcid.org/0000-0001-5147-4976

Dr. Mahender Singh - (D https://orcid.org/0000-0001-9016-759X

Dr. Mariya Khan - (1) https://orcid.org/0000-0002-2316-3182

Dr. Sanjeet Singh - (1) https://orcid.org/0000-0002-6922-2467

Kirti Bansal - (i) https://orcid.org/0000-0001-8497-0722

Source of support: None, Conflict of Interest: None
} 